\title{
Labeling of mechanically tenderized beef products: a mini review
}

\begin{abstract}
Mechanical tenderization of beef products involves mechanical techniques in order to break up tissue. This could lead to the introduction of pathogens from surface to the interior. Due to the huge number of outbreak reports related to mechanical tenderization since 2003, it becomes essential to standardize cooking time and instructions for consumer safety. Mandatory labeling of mechanically tenderized beef products is an innovative option to control the outbreaks. Labeling based on safe cooking time (end point internal temperature $160^{\circ} \mathrm{F}$ ) is dependent on various factors. This review discusses the process of tenderization, pathogenic organisms associated with it and cooking time factors. It also highlights the importance and pitfalls concerning labeling of validated cooking instructions.
\end{abstract}

Volume 3 Issue 2 - 2016

\author{
Joyjit Saha, Pushpinder Kaur Litt, Divya \\ Jaroni, Ravi Jadeja \\ Department of Animal Science, Oklahoma State University, USA
}

Correspondence: Ravi Jadeja, Robert M Kerr Food \& Agricultural Products Centre, Oklahoma State University, 106 FAPC Building, Monroe Street, Stillwater, OK 74078, USA, Tel + I (405)-744-3922, Email ravi.jadeja@okstate.edu

Received: August II, 2016 | Published: November 09, 2016

\section{Introduction}

Mechanical tenderization of meat products is now a usual practice in North America. ${ }^{1}$ Mechanical tenderization involves piercing or compression techniques to develop tenderized meat products. Growing concern of food safety with mechanical tenderization makes it essential to investigate the problem and develop control strategies. Although, mandatory labeling requirements of validated cooking instructions by U.S. Department of Agriculture's Food Safety and Inspection Service (USDA-FSIS) ensures consumer protection to an extent. But various factors governing cooking time makes it difficult to standardize or validate cooking instructions based on a particular parameter (thickness). ${ }^{2}$ This review aims to discuss mechanical tenderization process, strains associated with contamination: its illness or disease potential, control strategies involving cooking time dependent factors, labeling requirements and its ambiguities in certain areas.

\section{Discussion}

\section{Mechanical tenderization}

Consumers judge the palatability and quality of meat products based on their tenderness. ${ }^{3}$ To cater consumer preference, it necessitates assurance of quality tender products. Mechanical tenderization is an integral part of commercial beef processing. Mechanical tenderization of beef products guarantees continuous consistency in tenderness of beef products. ${ }^{4}$ It enhances consumer acceptability of inadequately tender raw beef. ${ }^{5}$ Mechanical tenderization of meat tissue in industries involves accepted techniques of blade or needlepiercing, pounding, compression and extrusion, slashing, or tumbling (massaging) ${ }^{4}$ Blade or needle tenderization is popular in Europe and North America. Blade or needle tenderization involves piercing them with closely spaced needles or small blades in order to break up the tissue or muscle fibers into shorter segments. Breaking of the connective tissue leads to release of myofibrillar proteins. Increased protein extractability causes solubilization during cooking leading to tenderness of beef muscle fibers. ${ }^{7}$ It has been further studied that mechanical tenderization reduced cooking times, hardness, and chewiness. ${ }^{8,9}$ Likewise they were found to increase mealiness, flavor and overall palatability. ${ }^{10}$ Lately, due to its positive attributes and consumer preference it has become the widely accepted technique within the meat industry, hotel, restaurant, and institutional trade. ${ }^{11}$ However, with the growing popularity of mechanical tenderization there has been issues of compromised food safety. Food safety concerns arise due to increased chances of carrying the surface bacterial microflora into previously sterile deep tissues with piercing of needles of blades. ${ }^{12}$ If cooked thoroughly, chances of contamination hazard is fairly low. But consumer preference for rare and medium cooked beef leads to survivability of contaminated pathogenic in underdone tissues. ${ }^{13}$ Among the pathogenic microflora studied tracing sources of contamination, Shiga toxigenic (STEC) Escherichia coli O157:H7 (E. coli O157:H7) and Non-O157:H7 and Salmonella species were found to be most abundant. ${ }^{14}$ Since 2000, the Center for Disease Control and Prevention (CDC) reported and identified E. coli $\mathrm{O} 157: \mathrm{H} 7$ as the causal microorganism of six outbreaks linked to needle or blade tenderized beef products. ${ }^{15}$ Likewise, in Canada E. coli O157:H7 was responsible for 18 food borne illness followed by an outbreak. ${ }^{16}$ Therefore, it becomes essential to review the concerned microbe: its occurrence, illness, and disease causing potential to design effective control strategies.

\section{Pathogens commonly associated with tenderized beef products contamination}

The global economic burden of pathogenic microbial contamination of beef products is estimated to be billions of dollars every year because of recalls, disposals, and health care costs. Recalls of food due to microbial contamination accounted for $25 \%$ of all food recalls in the US between October 1991 and September 1992. ${ }^{17}$ Moreover, contamination issues with foods is playing an increasingly important role in the economy of many countries having devastating effects on their foreign trade. ${ }^{17}$ On the other hand, microbial contamination of foods may cause severe economic losses to processing companies or entire industries if the microbial hazards are not recognized timely. ${ }^{17}$ So it becomes essential to recognize microbial hazards related to mechanically tenderized beef products. Some of the commonly associated microbial pathogens include: shiga toxin producing Escherichia coli $\mathrm{O} 157: \mathrm{H} 7$ and Non- O157:H7 (STEC), and Salmonella. 
STEC and Salmonella spp. are a part of the natural flora in the gastrointestinal tract of cattle and are shed in the feces which can sully the cattle hide leading to pathogen attachment where they persist for extended periods of time. Cattle hide was found to be the major source of STEC and Salmonella spp. ${ }^{18}$ Muscle and fat tissue surfaces beneath the hide of healthy cattle are essentially sterile, but they become contaminated when the carcasses come in contact with the hide during animal processing. ${ }^{18}$ Moreover, high prevalence of Escherichia coli O157:H7 around 76\% in cattle hides entering commercial beef plants makes it more vulnerable to contamination. ${ }^{19}$

The STEC was first identified in 1982 as a human pathogen from two outbreaks of hemorrhagic colitis (HC) occurred due to consumption of undercooked hamburger patties. ${ }^{20}$ The STEC infections showed distinctive clinical symptoms such as abdominal cramps, bloody stools with little or no fever. Subsequently Karmali et al. ${ }^{21}$ found its association with shiga like toxin production and postdiarrheal hemolytic uremic syndrome (HUS) which causes acute renal injury, and thrombocytopenia. It was reported that toxin was produced by diarrheagenic $E$. coli that had same immunological and functional characteristics as of Shigelladysenteriae. ${ }^{22}$ According to recent estimates of CDC, 48 million cases of food borne illness that occur every year, affect one in six Americans. More than 96,534 food borne illness and 61 deaths each year in the US are linked to E. coli $\mathrm{O} 157: \mathrm{H} 7$ infections. $^{23}$ Since 1998-2008, 350 E. coli O157:H7 associated outbreaks ( $52 \%$ food borne) were reported in 49 states, of which six of them were traced back to mechanically tenderized beef products. ${ }^{24}$ These studies suggest that $E$. coli $\mathrm{O} 157$ have emerged as an important human pathogen of public health concern. Other E. coli serotypes that can produce Shiga toxins and cause diarrhea, hemorrhagic colitis, and HUS have been emerged over the years. ${ }^{25}$ These new STEC serotype named non-O157 E. coli have emanated and are reported to cause 287,000 cases of illnesses each year contributing to the public burden of human infections and clinical diseases. ${ }^{23}$ According to the CDC in the year 2010 non-O157 E. coli serogroups collectively caused more human infections than E. coli $\mathrm{O} 157: \mathrm{H7}$ in the US. It has been estimated that approximately $70 \%$ of the non-O157 STEC infections that emerged from 1983 to 2002 were caused by one of six major serotypes, which are now referred to as "the big six," including O26, O45, O103, O111, O121, and O145. ${ }^{26}$ There have been 46 outbreaks attributed to these non-O157 E. coli strains alone in the US from 1990 to $2010 ; 84 \%$ of the illnesses in these outbreaks were food borne. Those 46 outbreaks were categorically attributed to O111 (14), O26 (11), O121 (5), O45 (4), O145 (2), O103 (2), and O104 (1). ${ }^{27}$ Therefore, it is evident that recently emerged non-O157 E. coli threatens public health and has been declared as an adulterant in nonintact beef by USDA.

With the ability to abode at ease in the gastrointestinal tract, Salmonella is the next big concern as causative agent of food borne illness. From 2009 to 2010, it resulted in the largest number of reported hospitalizations in US due to food borne disease outbreaks. ${ }^{18}$ Salmonella serotypes are linked to human Salmonellosis. There are 2449 known serotypes of Salmonella. ${ }^{28}$ Among the known serotypes, Salmonella Typhimurium (S. Typhimurium), Salmonella Newport (S. Newport) and Salmonella Enteritidis (S. Enteritidis) are the most commonly associated with food borne out breaks. From all the mentioned serotypes, $S$. Typhimurium caused havoc amounting to 458 cases of illness with 49 cases of hospitalization in the US and 813cases of illness in European countries like Iceland, the Netherland, the U.K., Germany and Finland. ${ }^{29-32}$ Salmonella is highly adaptive pathogen that can survive a range of adverse environmental conditions. These extreme conditions include desiccation and starvation, which the bacterium survives by reducing its cell surface area and minimizing metabolic activity. Salmonella spp. is also able to tolerate acidic conditions and have the ability to remain viable even in low relative humidity, and can withstand sunlight for at least 10days making it one of the most difficult organism to control.

\section{Control strategies and labeling requirements}

It becomes essential to control the growing number of food borne outbreaks linked to consumption of mechanically tenderized steaks due to STEC and Salmonella spp. Swanson et al. ${ }^{33}$ identified failure in effective cooking of mechanically tenderized raw or partially cooked beef product as a significant factor in related outbreaks. ${ }^{33}$ This necessitates to develop scientific cooking procedure based on temperature profile of meat, number of flipping's, and cooking time dependent factors. ${ }^{1,14}$ Previous studies and USDA-FSIS ${ }^{34}$ have suggested that maintaining a consistent temperature in beef products assured complete lethality of pathogenic flora. ${ }^{1}$ In order to achieve consistency in temperature profile throughout cooking it necessitates full thawing before cooking. ${ }^{35}$ Along with thawing, the end point internal temperature of the cooked steak should reach $160^{\circ} \mathrm{F}$ to assure complete $\log$ reduction $\left(5 \log _{10}\right)$ of pathogenic microflora like STEC and Salmonella. Studies in the past have standardized cooking temperatures and rest time needed to ensure $5 \log _{10}$ reduction (Table $1)$.

Table I Cooking temperature and rest time to ensure complete reduction (5 $\log _{10}$ reduction) during cooking of mechanically tenderized steaks

\begin{tabular}{llll}
\hline Pathogen & $\begin{array}{l}\text { Cooking } \\
\text { temperature }\end{array}$ & Rest time & Reference \\
\hline $\begin{array}{l}\text { Salmonella } \\
\text { and }\end{array}$ & $145^{\circ} \mathrm{F}$ & 3 minutes & \\
$\begin{array}{l}\text { Escherichia } \\
\text { coli }\end{array}$ & $150^{\circ} \mathrm{F}$ & 52 seconds & 37,38 \\
O157:H7 & Above $160^{\circ} \mathrm{F}$ & $\begin{array}{l}\text { No rest } \\
\text { time }\end{array}$ \\
\hline
\end{tabular}

Flipping of mechanically tenderized steaks is an essential factor deciding fate of pathogenic microflora. A study by Gill et al. ${ }^{1}$ identified more consistent reductions in E. coli O157:H7in those steaks which were flipped twice rather than turning them over once. Increased number of flipping's during cooking of mechanically tenderized steaks ensured consistent achievement of desired endpoint temperature throughout the steak.

In lines with control strategy through scientific cooking method, mandatory labelling requirements for NRTE mechanically tenderized steak products were announced by USDA-FSIS. Labeling requirements warrants safety of mechanically tenderized beef products based on validated cooking instructions. Validation of cooking instructions on the label is an integral part of food safety. Validated cooking instructions are generally standardized based on above mentioned factors and standard thickness ${ }^{34}$ of steaks. However, previous studies have shown multiple cooking time dependent factors like water content, humidity, type of meat and cooking method. ${ }^{36}$ Similar studies conducted in our facility have shown significant variation in safe cooking time (internal temperature: $160^{\circ} \mathrm{F}$ ) according to weights (identical thickness), water content and type of meat (unpublished data). Moreover, it was also observed that cooking time varied according to both subprimals and steak cuts (Strips-Strip loin etc., Chuck, Teres Major etc.). Therefore 
it becomes essential to conduct further studies on cooking validation procedures considering multiple factors for formulating labeling requirements of mechanically tenderized steak products. Although, large meat processing industries have specific product line (constant thickness and weight) that warrants validation of cooking instructions. But consumer preference for customized thickness and cuts from small and medium producers makes it difficult to generate validated cooking instruction labels. This makes both the processor and consumer vulnerable to contamination issues following legal hazards.

\section{Conclusion}

Foodborne illnesses are now considered as one of the most prevalent problems across the world. Consumer preference for minimal processing with antimicrobials and consumption patterns of raw to medium rare has left the industries with narrow spectrum. Effective research investigating various cooking time dependent factors is essential to formulate effective cooking instructions. Standardized cooking based on thickness needs further study. It also necessitates to incorporate multiple factors (meat type, cooking method, $\mathrm{pH}$, fat and water content, collagen content) to decide safe cooking time. No specified guidelines for small and medium scale processors selling customized steak products increases risk of contamination hazards. Effective risk evaluation of small and medium scale meat processors and designing mitigation strategies is the need of the hour

\section{Acknowledgements}

None.

\section{Conflict of interest}

The author declares no conflict of interest.

\section{References}

1. Gill C, Yang X, Uttaro B, et al. Effects on survival of Escherichia coli O157: $\mathrm{H} 7$ in non-intact steaks of the frequency of turning over steaks during grilling. Journal of Food Research. 2013;2(5):77.

2. Lowe B. Experimental cookery, from the chemical and physical standpoint 2nd ed. UK: J Wiley \& Sons; 1937. p. 969-970.

3. Boleman S, Boleman S, Miller R, et al. Consumer evaluation of beef of known categories of tenderness. J Anim Sci. 1997;75(6):1521-1524.

4. Pietrasik Z, Shand PJ. Effect of blade tenderization and tumbling time on the processing characteristics and tenderness of injected cooked roast beef. Meat Sci. 2004;66(4):871-879.

5. Brooks J, Belew J, Griffin D, et al. National beef tenderness survey-1998. J Anim Sci. 2000;78(7):1852-1860.

6. Tyszkiewicz I, Jakubiec-Puka A. Ultrastructure of mechanically tenderised pork muscle. Meat Sci. 1995;41(3):273-282.

7. Motycka RR, Bechtel PJ. Influence of pre $\square$ rigor processing, mechanica tenderization, tumbling method and processing time on the quality and yield of ham. J Food Sci. 1983;48(5):1532-1536.

8. Jeremiah L, Gibson L, Cunningham B. The influence of mechanical tenderization on the palatability of certain bovine muscles. Food Res Int. 1999;32(8):585-591.

9. Shackelford S, Reagan J, Mann T, et al. Effects of blade tenderization, vacuum massage time and salt level on chemical, textural and sensory characteristics of precooked chuck roasts. J Food Sci. 1989;54(4):843-845.
10. Smith G, Seideman S, Carpenter Z. Blade tenderization effects on cooking and palatability characteristics of steaks from bullock and cow carcasses. $J$ Food Protect. 1979;42(7):563-566.

11. Miller S. Mechanical tenderization of meat in the HRI trade proceedings 1975.

12. Gill CO, McGinnis JC, Rahn K, et al. Microbiological condition of beef mechanically tenderized at a packing plant. Meat Sci. 2005;69(4):811-816.

13. Johnston R, Harris M, Moran A. The effect of mechanical tenderization on beef rounds inoculated with Salmonellae. J Food Saf. 1978;1(3):201-209.

14. Luchansky JB, Porto-Fett A, Shoyer BA, et al. Fate of Shiga toxinproducing O157: H7 and non-O157: H7 Escherichia coli cells within blade-tenderized beef steaks after cooking on a commercial open-flame gas grill. J Food Protect. 2012;75(1):62-70.

15. Heiman KE, Mody RK, Johnson SD, et al. Escherichia coli O157 Outbreaks in the United States, 2003-2012. Emerging infectious diseases. 2015;21(8):1293-1301.

16. Catford A, Lavoie M-C, Smith B, et al. Findings of the health risk assessment of Escherichia coli $\mathrm{O} 157$ in mechanically tenderized beef products in Canada. International Food Risk Analysis Journal. 2013;3:32003.

17. Molins RA, Motarjemi Y, Käferstein FK. Irradiation: a critical control point in ensuring the microbiological safety of raw foods. Food Control. 2001;12(6):347-356.

18. Jadeja R, Hung Y-C. Efficacy of near neutral and alkaline $\mathrm{pH}$ electrolyzed oxidizing waters to control Escherichia coli O157: H7 and Salmonella Typhimurium DT 104 from beef hides. Food Control. 2014;41:17-20.

19. Arthur T, Bosilevac JM, Nou X, et al. Escherichia coli O157 prevalence and enumeration of aerobic bacteria, Enterobacteriaceae, and Escherichia coli $\mathrm{O} 157$ at various steps in commercial beef processing plants. $J$ Food Protect. 2004;67(4):658-665

20. Wells J, Davis B, Wachsmuth I, et al. Laboratory investigation of hemorrhagic colitis outbreaks associated with a rare Escherichia coli serotype. J Clin Microbiol. 1983;18(3):512-520.

21. Karmali M, Petric M, Steele B, et al. Sporadic cases of haemolytic-uraemic syndrome associated with faecal cytotoxin and cytotoxin-producing Escherichia coli in stools. The Lancet. 1983;321(8325):619-620.

22. O'Brien AD, LaVeck GD. Purification and characterization of a Shigella dysenteriae 1-like toxin produced by Escherichia coli. Infection and Immunity. 1983;40(2):675-683.

23. Scallan E, Hoekstra RM, Angulo FJ, et al. Foodborne illness acquired in the United States-major pathogens. Emerg Infect Dis. 2011;17(1):7-15.

24. Painter JA, Hoekstra RM, Ayers T, et al. Attribution of foodborne illnesses, hospitalizations, and deaths to food commodities by using outbreak data, United States, 1998-2008. Emerg Infect Dis. 2013;19(3):407-415.

25. Tarr PI, Neill MA. Perspective: the problem of non-O157: H7 Shiga toxin (verocytotoxin)-producing Escherichia coli. J infect diseases. 1996;174(5):1136-1139.

26. Brooks JT, Sowers EG, Wells JG, et al. Non-O157 Shiga toxin-producing Escherichia coli infections in the United States, 1983-2002. J infect diseases. 2005;192(8):1422-1429.

27. Luna-Gierke R, Griffin P, Gould L, et al. Outbreaks of non-O157 Shiga toxin-producing Escherichia coli infection: USA. Epidemiol Infect. 2014;142(11):2270-2280.

28. Chiu C-H, Su L-H, Chu C. Salmonella enterica serotype Choleraesuis: epidemiology, pathogenesis, clinical disease, and treatment. Clin Microbiol Rev. 2004;17(2):311-322. 
29. Takkinen J, Nakari U, Johansson T, et al. A nationwide outbreak of multiresistant Salmonella Typhimurium var Copenhagen DT104B infection in Finland due to contaminated lettuce from Spain, May 2005. Euro Surveill. 2005;10(6):E050630.

30. Crook PD, Aguilera JF, Threlfall EJ, et al. A European outbreak of Salmonella enterica serotype Typhimurium definitive phage type 204b in 2000. Clinical microbiology and infection. 2003;9(8):839-845.

31. Harvey J, Gilmour A. Occurrence and characteristics of Listeria in foods produced in Northern Ireland. Int J Food Microbiol. 1993;19(3):193-205.

32. Horby PW, O’Brien SJ, Adak GK, et al. A national outbreak of multiresistant Salmonella enterica serovar Typhimurium definitive phage type (DT) 104 associated with consumption of lettuce. Epidemiology and infection. 2003;130(02):169-178.

33. Laine ES, Scheftel JM, Boxrud DJ, et al. Outbreak of Escherichia coli O157: $\mathrm{H} 7$ infections associated with nonintact blade-tenderized frozen steaks sold by door-to-door vendors. J Food Protect. 2005;68(6):11981202 .
34. USDA-FSIS. FSIS Compliance Guideline for Validating Cooking Instructions for Mechanically Tenderized Beef Products; 2015.

35. Berry B. Use of infrared thermography to assess temperature variability in beef patties cooked from the frozen and thawed states. Foodservice research international. 2000;12(4):255-262.

36. Campbell L. Meathead: the science of great barbecue and grilling. In: Editor (ed)^(eds). Book Meathead; The Science of Great Barbecue and Grilling. New York 10010 USA; 2016.

37. Goodfellow S, Brown W. Fate of Salmonella inoculated into beef for cooking. Journal of Food Protection. 1978;41(8):598-605.

38. Line JE, Fain AR, Moran AB, et al. Lethality of heat to Escherichia coli 0157: H7: D-value and z-value determinations in ground beef. $J$ Food Protect. 1991;54(10):762-766. 